\title{
Geografia, marxismo e subdesenvolvimento
}

\author{
Milton Santos \\ Departamento de Geografia / FFLCH-USP
}

p. $166-172$

\section{revista}

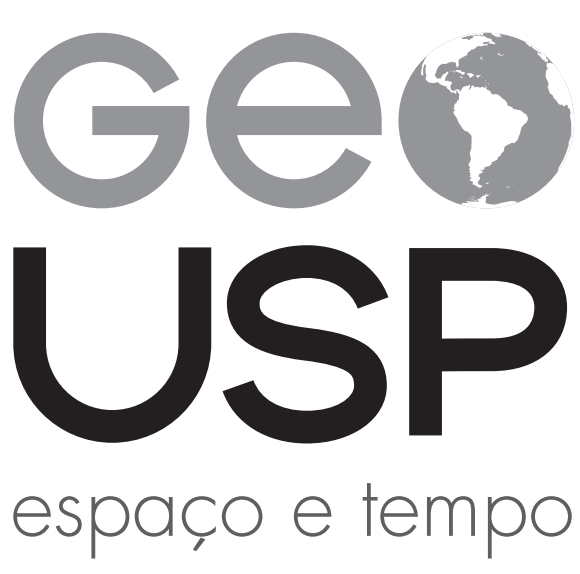

Volume 19, no 1 (2015)
Disponível em:

http://www.revistas.usp.br/geousp/article/view/97312

\section{Como citar:}

SANTOS, M. Geografia, marxismo e subdesenvolvimento. GEOUSP - Espaço e Tempo, São Paulo, v. 19, n. 1, p. $166-172,2015$.

\section{$(\mathrm{cc}) \overline{\mathrm{EY}}$}

Este artigo está licenciado sob a Creative Commons Attribution 4.0 License. 


\section{Geografia, marxismo e subdesenvolvimento}

Milton Santos ${ }^{1}$

As categorias do pensamento marxista não são inovações em Geografia. As razões pelas quais são raramente discutidas pertencem a dois tipos: (1) o relativo isolamento das chamadas "escolas nacionais" que ignoram frequentemente os avanços em outras línguas e (2) as ideias marxistas nunca alcançaram a marca de uma aprovação oficial. Os geógrafos marxistas, membros ou não do partido, foram mais que modestos em citar suas maiores fontes - Marx, Engels, Lênin ou Rosa de Luxemburgo. Provavelmente, esta foi uma forma de evitar serem denominados "tipos políticos", durante o período em que tal denominação era evitada pelos acadêmicos.

Esta atitude prevaleceu na França após a Segunda Guerra Mundial. Jean Dresch e Jean Tricart, ${ }^{2}$ antes de serem geomorfólogos, estiveram interessados em tópicos marxistas. $\bigcirc$ primeiro estudou o papel dos fluxos de capital na organização do espaço africano. $\bigcirc$ segundo estudou a estrutura interna das cidades (ecologia urbana) no contexto do conflito de classes, a propriedade da terra e o mercado especulativo da terra urbana. Isto foi o resultado da inflação, essencial a esta fase do capitalismo, e a exploração das externalidades (não reconhecidas explicitamente nestes termos, mas financiadas pela coletividade) através da criação de mais-valia.

Pierre George, leal à tradição da Geografia humana francesa, agrupou um certo número de geógrafos ativistas. Merece o crédito de haver estabelecido a importância das estruturas socioeconômicas na explicação geográfica. Suas primeiras publicações sobre população (19511959), Geografia social (1946) e seu tratado sobre as cidades (1952) demonstram seu esforço em abarcar a dinâmica dos sistemas socioeconômicos com as estruturas da produção. A Guerra

1 Título do original: Geography, Marxism and Underdevelopment, publicado em Antípode, v. 6, n. 3, p. 1-9, 1974. Traduzido da versão em espanhol por Ros Hari Zenha Kaupatez. Posteriormente publicado em "Reflexões sobre a geografia”, AGB São Paulo, 1980. Agradecemos à AGB São Paulo que autorizou a republicação desse artigo traduzido.

2 Em dois artigos publicados em La Pensée (1953; 1956), Jean Tricart fez uma distinção entre uma "geomorfologia marxista" e uma "geomorfologia burguesa". Tal ideia surgiu quando, durante seu período "heroico", reagiu contra a tradição imposta por W. M. Davis, tentando substituí-la por sua perspectiva dinâmica da geomorfologia. Não foi simplesmente por acaso que, mais tarde, Tricart converteu-se no fundador da geografia aplicada. Outros trabalhos com temas marxistas são os de Jean Suret-Canale (1948; 1949; 1967), Jean Dresh (1948) e Bernard Kayser (1951). 
Fria, sem dúvida, e a invasão da Hungria marcaram um ponto importante de mudança. Alguns seguiram as linhas marxistas muito discretamente, enquanto outros a abandonaram. Todavia, esta ideologia sobreviveu. A geografia necessitava, nesse momento, de uma ideologia coerente.

Os geógrafos "não envolvidos na política" buscavam alguns fundamentos teóricos. Começavam a adotar, inconscientemente, termos do vocabulário marxista: ${ }^{3}$ por exemplo, acumulação da renda urbana; ou melhor, teses que explicavam a cidade como uma criação da mais-valia rural. Sem conhecer sua origem, não tiveram dúvidas em usar uma interpretação marxista da evolução urbana durante o período de transição do feudalismo ao capitalismo e, inclusive, no contexto da pós-guerra. A noção de "ruralização urbana" que se apreende na literatura sobre "pequenas cidades" é também emprestada a Marx (1964, p. 78). Uma reflexão similar pode ser feita em relação à noção de "região urbana" definida como uma área na qual cidade e campo se complementam através de intercâmbios bilaterais. ${ }^{4}$ Uma frase-chave na Geografia francesa e americana é: "Não há cidade sem uma região, nem há região sem uma cidade". Efetivamente, este foi um clichê desprovido de significado sólido.

\section{Geografia (espaço) e categorias marxistas}

As contradições existentes nas extremas concentrações de poder dos gigantes Estados-corporações renovaram o interesse por Marx e seus discípulos (ortodoxos ou não), como fontes de explicação geográfica (sobre as dimensões geográficas deste problema, ver Santos, 1974; 1975). As desigualdades econômicas e sociais, a decrescente participação do povo na tomada de decisões geram uma alienação social e econômica, com importantes efeitos na organização do espaço. Isto é uma realidade em todas as escalas da observação geográfica.

Duas importantes questões metodológicas, pelo menos, surgem deste problema: primeiro, como se pode entender - em termos de variáveis - a totalidade; segundo como se pode interpretar o presente significado de espaço em termos de tempo acumulado. ${ }^{5}$ A noção de totalidade somente pode ser relacionada com o mundo como um todo. Por outro lado, o espaço nacional é contínuo, como o é o espaço de suas partes, e assim a noção de escala é fundamental. ${ }^{6}$ Os elementos definidores do espaço, consequentemente, deveriam ser considerados como variáveis cuja natureza e significação variam segundo o nível (de espaço) considerado. O problema da delimitação espacial assume outra dimensão, já que cada uma das partes é supostamente uma réplica da totalidade. Este objetivo torna-se particularmente difícil, já que a Geografia, nos seus esforços de especialização, fragmentou-se e tem fragmentado também a realidade que ela estuda. Ao selecionar várias ideias de diferentes fontes, a Geografia burguesa foi incapaz de interpretar o todo. Em muitos casos, poder-se-ia dizer que esta foi uma ignorância deliberada.

\footnotetext{
3 Esses geógrafos assumem uma perspectiva muito oposta à de Vidal de La Blache e seus primeiros discípulos. Estes estiveram muito conscientes da noção marxista de totalidade quando falaram de "unidade terrestre", mas não seguiram desenvolvendo a ideia, do mesmo modo que não se aprofundaram na noção de possibilismo.

4 "A cidade, com seu território circundante, formou o todo econômico" (Marx, 1964, p. 79). (O MSS está fechado 1857 1858.)

5 Com relação a esse tema, veja-se "Modernisations et espace derivés", Tiers Monde, n. 50, por Milton Santos, ec. (Paris: Presses Universitaires de France, 1972).

6 Essa ideia tem sido desenvolvida por outros: David Harvey (1969) e Yves Lacoste (1966; 1973).
} 
Por outro lado, quando se têm explicado os aspectos dinâmicos da Geografia, a noção de sistemas "espaciais-temporais" tem sido utilizada, mas geralmente espaço e tempo têm sido considerados como categorias independentes. Infelizmente, a significação do tempo não foi bem fundamentada, e a perspectiva transtemporal foi escassamente desenvolvida, até um ponto em que, não obstante, os modelos de difusão permaneceram medíocres.

que se pode dizer sobre o presente? Isso é muito difícil hoje, quando, segundo Maurice Dobb (1963, p. 12), o tempo de mudança é "anormalmente acelerado". Tais fases revolucionárias representam transições entre períodos históricos. Contudo, é muito mais conveniente lidar com ritmos temporais (sistemas), que são relativamente definíveis em termos de períodos de rupturas. A velocidade da mudança aumenta a amplitude do desconhecido e pode encobrir a hierarquia real de variáveis em um mundo caracterizado pela instabilidade.

Estas dificuldades significam um desafio. Não se pode aplicar a análise marxista à interpretação do espaço enquanto aquelas categorias marxistas relacionadas com a geografia não forem operacionalizadas. Isto significa que não se podem usar categorias convencionais, já que não serão obtidas em textos oficiais.

Noções marxistas, como a de mais-valia, podem ser aplicadas, como o fez Harvey (1973), ${ }^{7}$ a situações sociais empíricas. É neste sentido que Harvey assinalou certas debilidades fundamentais na teoria da renda (Alonso, 1964). Outras ideias poderiam ser similarmente aplicadas: por exemplo, a acumulação e circulação do capital; o impacto da inovação no capital monetário, capital fixo e capital circulante; valor de uso e valor de troca; modo e estrutura da produção; estrutura de classes... são todas categorias que podem ser levadas à linguagem espacial ou geográfica.

Os êxitos alcançados por autores como Harvey, Bunge, Eichenbaum e outros na investigação da estrutura interna das cidades, deveriam ser seguidos por estudos similares sobre externalidades, ou a natureza integral do espaço. Isto pressupõe algumas questões metodológicas. A unidade fundamental para o estudo geográfico deveria ser a Nação-Estado. Não se pode dissociar a noção de sistema da noção de um sistema de estruturas (Santos, 1974). Nesta perspectiva, poder-se-ia utilizar todo o poder explicativo das múltiplas forças dialéticas no espaço. Se o espaço é concebido como um todo, então a distinção artificial entre "espaço econômico" e "espaço geográfico" poderia ser abolida (Santos, 1971; 1974a). Dever-se-ia conceber o espaço como um todo e não como um espaço aristocrático onde os fluxos estudados são unicamente aqueles das grandes empresas e população burguesa. Isto produziria uma verdadeira Geografia da pobreza, uma Geografia onde riqueza e pobreza não fossem tratadas como entidades separadas, mas como partes complementares de uma só realidade.

\section{Um espaço subdesenvolvido?}

A geografia dos países desenvolvidos coloca a questão de como definir o espaço. É possível chegar a uma definição universal de espaço, como um tipo de chave-mestra? A Geografia burguesa tentou fazê-lo: o subdesenvolvimento foi simplesmente um apêndice ou um capítulo suplementar nos manuais "gerais".

7 Em publicação recente (1973), David Harvey lança nova luz sobre o estudo dos problemas urbanos. Todo o conjunto de ideias que desenvolveu em conexão com as relações entre "justiça social" " "sistemas espaciais" permitiu-lhe articular uma vigorosa crítica à teoria da renda de Alonso (1964) e propor um enfoque alternativo ao problema, tal como o vemos em seu estudo "Real Income Redistribution in an Urban System" (p. 50/59). 
Sem dívida, aquelas variáveis formadoras do espaço e suas combinações, as quais originam as diferenças entre lugares, são universalmente as mesmas. $\bigcirc$ problema é descobrir se estas combinações se manifestam espacialmente e se sua manifestação é a mesma no centro e na periferia do sistema mundial. Neste sentido, pelo menos três aspectos são essenciais: 1) aquelas forças que promovem a modernização e que operam no centro do sistema não alcançam a periferia ao mesmo tempo; existe um efeito decrescente definido da distância. Isto poderia explicar historicamente a acumulação do capital no sistema capitalista, as variações entre países e as desigualdades regionais dentro dos países; 2) alguns pontos no espaço são alcançados por novas forças, enquanto outros não recebem tais impactos. Sem dúvida, esses impactos não se dão ao acaso, sendo dirigidos do centro do sistema em termos de máxima produtividade. A história do espaço é assim de tipo seletiva; 3 ) as forças emitidas dos centros (polos) mudam à medida que alcançam a periferia. Ainda que se possa encontrar isomorfismo, o valor do fenômeno é diferente. Por exemplo, a noção de "cidade primada" na França, ou de "metrópole incompleta" nos Estados Unidos e Alemanha, não pode ser interpretada da mesma forma nos países subdesenvolvidos.

○ "espaço subdesenvolvido" tem um caráter específico; as prioridades de importância variam, mesmo quando operam as mesmas forças, já que suas combinações e resultados são diferentes. É algo que os geógrafos ocidentais têm tido grande dificuldade em entender. Por que nós não podemos, então, reunir a experiência surgida nos países subdesenvolvidos: desenvolver teorias que tenham sentido tanto para os geógrafos como para os cidadãos? Atualmente, a Geografia "oficial" funciona como se o Ocidente tivesse o monopólio das ideias. Além disso, há muitos geógrafos do Terceiro Mundo que preferem permanecer silenciosos; ${ }^{8}$ sem divida, existem geógrafos ocidentais que estão começando a repensar muitos problemas do Terceiro Mundo. ${ }^{9}$ Isto é muito importante, já que nós não temos uma ideologia global que possa ser aplicada aos países subdesenvolvidos. Há um risco, então, de superpor categorias marxistas sobre uma superfície débil.

É urgente que uma teoria seja formulada: e o método dialético é adequado para um contexto onde múltiplas forças externas e internas; passadas e presentes; políticas, econômicas e sociais, enfrentam-se constantemente.

8 Não se pode deixar de lado o fato de o sistema universitário, em muitos países subdesenvolvidos (especialmente na África), ser ainda relíquia do colonialismo: estão organizados de tal forma que as decisões concernentes ao futuro dos jovens professores repousa nas mãos de "patrões" ocidentais ou ocidentalizados.

9 Entre os estudos que conhecemos, podemos citar os de T. G. McGee (1970a; 1970b; 1971; 1973); ele tem sido o pioneiro de toda uma série de estudos sobre urbanização, desenvolvendo um conjunto de indicações através das quais categorias marxistas podem ser articuladas. A Harold Brookfield (1973) devemos a transposição espacial das noções de dominação e dependência. B. Kayser (1972; 1973) tratou de problemas de "alienação regional" na Europa e na América Latina. $\bigcirc$ Cendes (Centro de Estudos del Desarrollo), da Universidade da Venezuela, desenvolveu um enfoque multidisciplinar para os processos sociais. Outros (não podemos citá-los todos) esquematizaram as fases da organização espacial na América Latina que estão associadas aos tipos de produção característicos de períodos específicos (M. Acosta; I. Segnini; G. Yanes, 1973). Catherine Paix (1972) explorou as relações entre modos de produção, evolução demográfica, tendências de emprego e urbanização. 


\section{As frentes de avanço}

Participar de uma renovação radicai da Geografia é um desafio tentador. Isto provavelmente explica o entusiasmo com que este tópico E considerado nos Estados Unidos, Grã-Bretanha e França. ${ }^{10}$ Alguns, sem dúvida, não apreciaram a seriedade desse trabalho. Algumas observações sobre este assunto são aqui sugeridas em forma de conclusão.

Este movimento é bem-vindo por diversas razões: permite-nos reconhecer a hegemonia que a chamada "revolução quantitativa" tem mantido no recente desenvolvimento da Geografia. Pode-se, assim, denunciar este tipo de dogmatismo cientifico que está mais interessado na verificação de hipóteses que na fonte e natureza destas hipóteses (Doberty, 1974, p. la). Este tipo de arrogância ("o mais destrutivo de todos os vícios acadêmicos", Freeman, 1961, p. 38) não conduz a nenhum tipo de progresso. Pode-se denunciar também o uso de linguagens obscuras (o leitor fica com a impressão de que está dirigida somente a pessoas realmente científicas). Liberados de tais vícios, pode ser mais fácil impedir a formação de clichês, os quais se sustêm através de recíprocos rituais de citações bibliográficas, e proceder sob a forma de discussões abertas. $\bigcirc$ marxismo permanecerá empobrecido até que tal situação seja alcançada. Tem-se que afastar, é claro, exercícios puramente acadêmicos. As citações bibliográficas são úteis para dar embasamento a uma ideia ou explicá-la melhor, mas não têm valor intrínseco em si mesmas. É bastante ridículo ver como alguns autores citam cegamente Marx, Engels, Lênin e Rosa de Luxemburgo, geralmente fora de contexto.

Uma boa coleção de enunciados não tem necessariamente maior significação: "Elegância não significa relevância"; uma sofisticada demonstração de um problema não é necessariamente melhor que uma explicação simples. A Sociologia latino-americana tem sido vítima de uma "diarreia retórica" - tal como Anibal Quijano (1973, p. 46) a tem criticado: "Se somos incapazes de abandonar esta atitude persistente de discutir nossos problemas em termos ideológicos [...] Eu creio, tu crês, nós cremos, Lênin pensou, Trotsky creu, Stalin afirmou, Mao disse [...] será impossível fazer algum progresso".

Finalmente, não é suficiente seguir uma corrente que possa resultar simplesmente em outra moda passageira. Tem-se que selecionar os aspectos mais apropriados e úteis aos estudos geográficos: aspectos apropriados à realidade do presente e ao caráter espacial dos lugares. Por outro lado, não se deve vacilar em usar todas as evidências - históricas, filosóficas ou empíricas - porque o perigo de ser dogmático estará sempre presente. $\bigcirc$ valor de tais instrumentos de análise será julgado dentro de um contexto de ação social e a partir de uma perspectiva dialética. $\bigcirc$ risco de convertermo-nos em inúteis é também herdado do marxismo clássico. A crítica que Engels fez a Buchner, Vogt e Moleschott não se baseava (de acordo com Lênin, 1967, p. 227) no fato de que estivessem em desacordo com Marx, mas no fato de que eles foram "materialistas vulgares": não desenvolveram uma teoria maior que a de seus mestres.

10 Nos Estados Unidos e na Grã-Bretanha, a revista Antípode é o principal expoente dessa tendência. Na França, Hérodote, sob a direção de Yves Lacoste, está prestes a aparecer. O título Hérodote lembra o papel político da Geografia na Grécia: o geógrafo grego foi uma fonte primária de informação. [O n. 16 de Hérodote saiu em 1979. (N.E.). 


\section{Referências}

ACOSTA, M.; SEGNINI, I.; YANES, G. Problemática del subdesarrollo: modalidades de ocupación del espacio en Latino-América. Caracas: Universidad Central, 1973.

ALONSO, W. Location and Land Use. Cambridge: Massachusetts, 1964.

BROOKFIELD, H. C. On One Geography an a Third World. Institute of British Geographers Transactions, n. 58, March 1973.

Colonialism, Development and Independence: The case of the Melanesian Islands in the South Pacific. London, 1972.

DOBB, M. Studies in the Development of Capitalism. London: Routledge and Kegan Paul, 1963.

DOHERTY, J. The role of Urban Places in Socialist Transformation (Some Tentative and Introductory Notes). University of Dar es Salaam, Department of Geography, 1974a. (Working paper mimeo.)

. Introduction: Geographic Research and Methodology. Journal of the Geographical Association of Tanzania, v. 10, p. 1-3, April 1974b.

DRESCH, J. Réflexions sur la géographie. La Pensée, n. 18, p. 87, 1948.

FREEHAN, T. W. A Hundred Years of Geography. London, 1961.

GEORGE, P. Introduction a l'Etude Géographique de la Population du Monde. Institut National d'Études Démographiques. Travaux et Documents, n. 14, Paris, 1961.

. La Ville: le fait urbain a travers le monde. Paris: Presses Universitaires de France, 1952. . Géographie Sociale du Monde. Paris, 1946.

GUGLIELMO, R. Géographie et dialectique. La Nouvelle Critique, n. 68, sept./oct. 1955.

HARVEY, D. Social Justice and the City. Baltimore, 1973.

Explanation in Geography. London, 1969.

KAYSER, B. De l'objectivisme au confusionisme dans l'enseignement de la Géographie. La Pensée, n. 35, p. 10, 1951.

. Le nouveau système de relations ville-campagne. Espaces et Sociétés, Paris: Anthropos, n. 8, 1973.

LA BLACHE, V. Principes de Géographie Humaine. Paris: Martonne, 1922.

LACOSTE, Yves. La géographie. In: CHATELET, F. Philosophie des sciences sociales. Paris, 1973.

. Le concept de sous-développement et la géographie. Annales de Géographie, p. 644670, 1966.

LENIN, V. I. Materialism and Empiro-criticism: Critical Comments on a Reactionary Philosophy. Moscou, 1967. 
MARX, K. Pre-Capitalist Economic Formations. London, 1964. (Manuscript: 1857-1858.)

MCGEE, T. C. The Persistence of the Proto-Proletariat: Occupational Structures and Planning of the Future World Cities. Australian National University, Research School of Pacific Studies, Department of Human Geography, April 1974. (Mimeo and bibliography.) . Peasants in the cities: a paradox, a paradox, a most ingenious paradox. Human Organization, v. 32, n. 2, p. 135-142, 1973.

. The Urbanization Process in the Third World. London, 1971.

Dualism in the Asian City: The Implications for City and Regional Planning, Centre of Asian Studies Reprint Series n. 2, University of Hong Kong, 1970a.

Hawkers in Selected Asian Cities: A Preliminary Investigation. Centre of Asian Studies, University of Hong Kong, 1970b.

PAIX, C. Approche théorique des problèmes de l'urbanisation. Tiers Monde, n. 50, 1972.

QUIJANO, A. Alternativas de las Ciencias Sociales en América Latina. Desarrollo Indoamericano, año 6, n. 21, p. 45-47, oct. 1973.

SANTOS, M. The Shared Space: the two circuits of urban economy in underdeveloped countries and their spatial implications. Methuen, 1975.

Sous-développement et poles de croissance économique et sociale. Tiers Monde, n. 58, p. 271-286, 1974a.

. L'Espace Partagé: les deux circuits de l'économie urbaine des pays sous-développés et leurs répercussions spatiales. Paris, $1974 \mathrm{~b}$. . Le Métier du Géographe. Paris, 1971.

SEVE, L. Panorama de la philosophie française contemporaine (II): le matérialisme depuis 1920. La Pensée, n. 90, p. 56-76, mars-avril 1960.

SLATER, D. Underdevelopment and spatial Inequality. London: Pergamon Press.

SURET-CANALE, J. Sur la géographie du sous-développement. La Pensée, n. 131, p. 14-21, févr. 1967.

. Encore quelques réflexions sur la géographie. La Pensée, n. 26, p. 26, 1949.

. L'exploration coloniale est-elle une réalité scientifique? La Pensée, n. 16, p. 13, 1948.

TRICART, J. Premier essai sur la géomorphologie et la pensée marxiste. La Pensée, n. 47, p. 62, 1953.

. La géomorphologie et la pensée marxiste. La Pensée, n. 69, p. 56-76, sept./oct. 1956. L'habitat urbain. Paris: CDU-Sedes, [s.d.]. 